\title{
A Three-dimensional Framework of Acculturation in translation of Musicals
}

\author{
Li JIN \\ School of International Studies \\ Zhejiang University \\ Hangzhou, China \\ lychee0111@zju.edu.cn
}

\begin{abstract}
In recent years, more and more classic western musicals have been staged in China with the dialogue and lyrics translated into Chinese, forming a new way of intercultural communication between Chinese and western theatrical arts. For the purpose of guiding the translation practice, this paper focuses on the remarkable phenomenon of acculturation in translation practice of musicals, and proposes a three-dimensional framework to explore its determining factors, specific requirements and typical strategies. The paper arrives at three conclusions. First, acculturation is necessary and inevitable in translation of musicals owning to three factors, namely cultural differences, audience reception, and the audiovisual constraints of music and performance. Second, the target text of a musical should be comprehensible, acceptable, and enjoyable (i.e. being both singable and interactive) for the target audience. Third, in order to meet these requirements, a translator has to acculturate the target text by applying such strategies as adapting cultureloaded expressions, filtering information of cultural conflicts, following the target-culture genre conventions of song lyrics, and making recreationalized adjustments.
\end{abstract}

Keywords-acculturation; translation of musicals; comprehensibility; acceptability; enjoyability

\section{INTRODUCTION}

Musical theatre (often abbreviated as "musical"), a vibrant theatrical form originated and popular in western countries, has been introduced into China for over a decade. In recent years, more and more classic western musicals, such as Mamma Mia!, Cats, Avenue Q, Man of La Mancha, and The Sound of Music, have been staged in China with native cast members performing in Chinese. Many of these shows attracted a large audience and turned out to be great successes.

In the production of these Chinese versions, the translation of the dialogue and lyrics is a significant yet quite challenging task, demanding a translator to consider a number of extratextual factors, especially when encountering intercultural problems. Acculturation of the exotic elements is usually a quite prominent phenomenon in translation of musicals. However, due to the relatively late start of the translation practice, the phenomenon has received scant attention in the academic community. On this account, this paper investigates the determining factors, specific requirements and typical strategies of acculturation in translation of musicals by proposing a three-dimensional framework.

\section{DETERMINING FACTORS OF ACCULTURATION IN TRANSLATION OF MUSICALS}

Acculturation is originally an anthropological term referring to "those phenomena which result when groups of individuals having different cultures come into continuous first-hand contact, with subsequent changes in the original cultural patterns of either or both groups" [1]. Later scholars of translation studies, such as Susan Bassnett, André Lefevere, Sirkku Aaltonen, introduced the concept into the study of theatre translation. In translation process, a foreign play is transplanted to a new environment and restricted by the theatrical system of the receiving culture [2]. A translator often needs to moderately adapt the exotic elements of the source text, resulting in changes in the target text compared with the original one. Such phenomenon resembles the anthropological concept of acculturation.

According to Aaltonen, a certain extent of acculturation is inevitable and more noticeable in drama translation than in translation of other text types [3]. Nevertheless, in translation of musicals, a special theatrical form, acculturation is even more remarkable because of three factors, i.e. cultural differences, audience reception, and the audiovisual constraints of music and performance.

\section{A. Cultural Differences}

At the macro level, there are fundamental differences between the eastern and western traditions of theatrical culture. As a form of theatrical performance combining songs, acting and dance, musicals are apparently similar to Chinese traditional operas. In fact, the two can be distinguished by many aspects such as cultural attributes, theatrical notion, performing systems, music, and stage design [4]. Hence it is essentially a kind of acculturation when western musicals breaking the boundaries of theatrical systems and being integrated into the Chinese theatrical culture. At the medium level, the contents or subject matter of a musical inevitably involve exotic elements of the western culture, which may cause communication barriers, even conflicts, to the audience in China. At the micro level, as a type of genre and a product of cultural development, song lyrics in different languages have respective genre conventions. As a result, a target text of musical lyrics, if rendered literally, may fail to give auditory pleasure to the target-culture listeners. To solve these problems, 
the translation of musicals is bound to make significant adaptations.

\section{B. Audience Reception}

In theatre translation, the intended readers such as the director, actors and band members are merely target-text users, while the audience constitutes the target-text receivers who finally decide the success or failure of a translated theatre work According to Hans-Robert Jauss's reception theory, an individual's understanding of a work occurs within a "horizon of expectation", that is, "an intersubjective system or structure of expectations" [5] that a reader possesses depending on his or her literary attainments and previous reading experience. Such expectations prescribe a limited frame for a reader's reception of a work. While enjoying a musical, the audience also has such "horizon of expectation" towards the show as well as the songs. As for a translated musical, the "horizon of expectation" of the receiving culture may contradict with that of the original. Therefore, acculturation is often necessary in translation practice of musicals so as to facilitate their reception.

\section{Audiovisual Constraints}

Translating musicals means not merely the conversion of verbal signs, but involves a number of extra-textual factors due to its audiovisual constraints of music and performance. On the one hand, the pre-existing musical score requires the words to be compatible with the music and sound natural when sung. However, the match of verbal signs and musical notation is an arduous task. According to Nida, "the translation of songs almost always means considerable formal adjustments" [6]. Likewise, in translation of musicals, a target text without acculturation often fails to match the music. On the other hand, as work in theatre semiotics has shown, it is only in performance that the full potential of a theatre text can be realized [7], which imposes both temporal and spatial restrictions on the translation of musicals. For one thing, unlike the sequential process of writing and reading of a literary work, the performance and appreciation of a musical happen simultaneously. Consequently, the audience can only apprehend the words on first encounter, demanding the language of the target text to be concise and intelligible. For another, unlike the rather personal experience of reading anywhere anytime, the audience of a theatre work collectively appreciates the show in the theatre during a certain period of time, which requires the translator to lay emphasis on the prospective performing effectiveness of the show. All of these restrictions highlight the need for acculturation in translation of musicals.

\section{REQUIREMENTS AND TYPICAL STRATEGIES OF ACCULTURATION IN TRANSLATION OF MUSICALS}

Given that the adjudicator of a translated theatre work is the audience, the specific requirements and typical strategies of acculturation are elaborated in the following three aspects from the perspective of audience reception.

\section{A. Acculturation for the Comprehensibility of the Target Text}

Comprehensibility is a basic requirement of acculturation. It is quite difficult to achieve in translation of musicals owning to the contradiction between cultural differences and audiovisual constraints. First, as is mentioned above, there is limited time for the target audience to digest the exotic elements during the performance, and the instantaneousness of theatrical performance excludes the possibility of annotation for culture-loaded expressions. Second, the number of Chinese characters of the target text is strictly limited by the number of syllables of the source text (which is normally the same as the number of musical notes), because any increase or decrease of the number will fail to match the rhythm of the pre-existing music. Hence in many cases, acculturation may well be the only possible choice, and a common strategy is adapting culture-loaded expressions.

Take the musical number "The Journey to the Heaviside Layer" from the classic musical Cats as an example. Near the end of the show, Grizabella the old Glamour Cat is chosen to be reborn to a new life. When she ascends gradually to the sky, all the other cats look up at her and sing the following two lines repeatedly and solemnly: "Up up up/ past the Russell Hotel, Up up up up/ to the Heaviside Layer". Here "Russell Hotel" is a landmark in the central area of London, while "the Heaviside Layer" is a layer of the earth's ionosphere, which is symbolically referred to paradise by the cats of Jellicle tribe in the show. These two proper nouns are hardly intelligible for the Chinese audience in view of the limited time of live performance. In the Chinese version, the two lines are rendered as “飞飞飞/越过高高山巅，插上翅膀/飞到九重高天” (which literally means "Fly fly fly/ past the high mountain peak, With a pair of wings/ Fly to the ninth layer of the sky"), in which the proper nouns are respectively replaced by “高高山 巅” and “九重高天”. The former expression makes a general reference of the line's substantial meaning of ascending, while the latter is an expression symbolizing heaven in the Chinese culture. With such adaptations, the target text turns to be readily comprehensible for the Chinese audience.

\section{B. Acculturation for the Acceptability of the Target Text}

The audience of a translated musical can either accept or reject the target text. As is previously mentioned, the "horizon of expectation" of the audience prescribes a limit for their reception of a theatre work. Owning to distinctions in aspects such as national characteristics, religions, ethics, and aesthetic tastes, receivers of different cultural backgrounds have different expectations towards the contents and subject matter of a theatre work. Accordingly, a musical meeting the "horizon of expectation" of the audience in western countries may cause conflicts and thus be inacceptable to the audience in China.

In order to acculturate the target text to the "horizon of expectation" of the target audience and facilitate its acceptation, a translator of musicals usually has to detect the information of potential cultural conflicts in the contents or subject matter of the work, and then filter the information in flexible ways. For instance, in the musical number "Dancing Queen" of Mamma Mia!, the middle-aged heroine Donna and her best friends sing and dance to recall their youthful years. In the lines "You're a 
teaser, you turn 'em on/ Leave 'em burning and then you're gone", the word "teaser" and the expression "turn 'em on" portray the image of a passionate girl. Nevertheless, according to the traditional Chinese values, young ladies must be elegant and shy and act passively in a relationship. Therefore, in the target text, the two lines are rendered as “你把他欲望开了头/ 放了一把火就想走” (which literally means “You start his desire/ Set a fire and then you want to leave"), in which the sensitive word and expression have been filtered naturally, avoiding possible cultural conflicts and ensuring the audience's acceptation of the show.

\section{Acculturation for the Enjoyability of the Translated Musical}

Enjoyability is an advanced requirement of acculturation in translation of musicals. The success or failure of a theatre work largely depends on the aesthetic experience of the audience, and only a translated musical full of audiovisual enjoyment can attract the audience. Given that the translation of musicals is restricted by the pre-existing musical score and the subsequent theatrical performance, the enjoyability of a translated musical can be further classified into two aspects, i.e. the singability of the target text, and the interactivity between the actors and the audience. In the case of acculturation, the former one requires a translator to moderately adjust the target text to the targetculture genre conventions of song lyrics; while the latter one often leads to recreationalized adjustments of the target text.

1) Singability and the target-culture genre conventions of song lyrics

A translator of musicals must attach great importance to the singability of the target text, which demands the target text to be adapted to the musical line and sound natural when sung, bringing auditory pleasure to the target audience. As the European melopoetic norm requires, a singable lyric displays a prosodic, poetic, and perhaps even a semantic-reflexive match to the music [8]. In translation of musical theatre, the musical structure and mood conveyed as well as the singing style of each musical number should be considered in the first place, and then every line of the lyrics should be set to the musical score in such micro aspects as syllable count, accent, sounds for easy singing, and location of key words. Besides, as is mentioned above, the target text also needs to adhere to the target-culture genre conventions of song lyrics. In the case of English-Chinese translation, a musical translator should pay extra attention to the particular rhyming rules of Chinese song lyrics and the tone changes of Chinese characters.

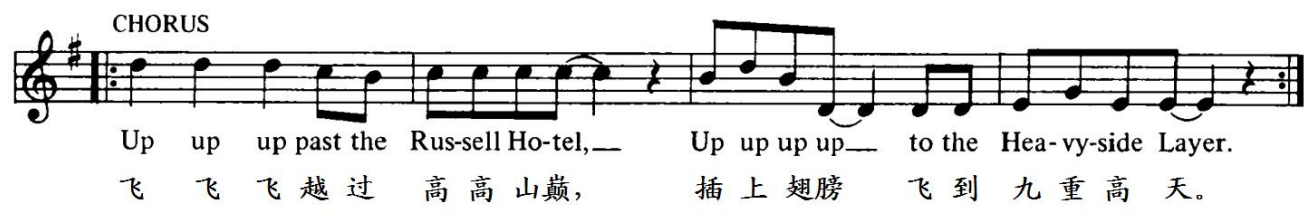

Fig. 1. Music to the first two lines of "The Journey to the Heaviside Layer"

As for the convention of rhyming, a basic rule is that Chinese song lyrics prefer dense and unified rhymes [9]. In the aforesaid example of "The Journey to the Heaviside Layer", the cited two lines in the source text is unrhymed, yet those in the target text end with the same vowel sound an ("巅 (dian)" and "天 (tian)"). The reason lies in that the entire musical number is short and simple; if with no end-rhymes, such kind of lyrics in Chinese is not catchy enough during performance.

As for the convention of tone changes, it should be emphasized that the tones of Chinese characters would possibly change under the influence of pitch change when sung. Once the rising and falling of tones goes against that of pitches, the meaning of phrases may be ambiguous or mistaken. Such problem of tone changes not only affects the possibility of natural singing for the actors, but also harms the instant understanding and the auditory pleasure of the words for the audience.

Again translation of "The Journey to the Heaviside Layer" is presented as an instance. As the musical score in Fig. 1 indicates, the pitches of the repeated prepositions "up" in the first line keep unchanged; whereas, those in the second line ascend and descend rapidly with large intervals between two adjoining pitches, making it impossible to render every "up" with the same Chinese character. In the target text, the repeated four prepositions in the second line are creatively translated into “插上翅膀” with the last character of the falling-rising tone, which not only adds a special sense of poetic beauty to the lyrics, but also ensures the compatibility of the words and the music. In addition, it should be noticed that each syllable of the proper noun "Russell Hotel" is placed on the same pitch, and all the four characters of the corresponding target text “高 高山巅” are of the high and level tone and perfectly match the pitch of the music. As a result, the target text of the whole musical number can be sung fluently and naturally to the music, as well as be pleasant to ears for the target audience in China.

\section{2) Interactivity and recreationalized adjustments of the} target text

According to French theatrical semiotician Anne Ubersfeld, the written text is incomplete in itself, and any notion of theatre must see written text and performance as indissolubly linked [10]. Pavis also argues that theatre translation is a kind of language conversion transcending the written text and the translation practice should actually be conducted on the level of stage performance [11]. Among the various qualities of theatrical performance, an essential one is the interactivity between the actors and the audience. On the one hand, the audience can give real-time feedback to the actors on the stage; on the other hand, the actors can improve their performance according to the instant response of the audience. As a recreational business, the art of musicals also highlights the 
need for such interaction. Accordingly, a translator of musicals needs to take interactivity into account and accommodate the target text to the future performing atmosphere in the theatre. Here a common convention is the recreationalized adjustments of the target text, such as including elements of domestic or local features.

For example, in the Chinese version of Avenue $Q$, a musical comedy addressing and satirizing the issues and anxieties associated with entering adulthood, expressions such as “没钱 还房贷 (have no money to pay house loan)”, “没车没房 (have no car and no house)”, “看城管降临小贩乱逃 (see the city inspectors coming and the peddlers running away in a hurry)", are closely relate to the Chinese social life and thus can easily arouse sympathy from the audience of young people. In Cats, while translating the musical number introducing Bustopher Jones, a cat of noble birth, the translator even rewrites a whole stanza in a recreationalized manner. The stanza about restaurants and delicacies which can hardly set to the music if rendered literally is replaced by the praise of Chinese cuisines in Chinatown, such as “小笼包 (small steamed buns)”, “烤鸭 (roast duck)” and “茅台 (Moutai, a famous brand of distilled Chinese liquor)". Consequently, when the chubby cat sings the target text on the stage, the audience often roars with laughter. Hence it can be seen, proper recreationalized adjustments often successfully shorten the distance between the actors and the audience and thus contribute to the performing effectiveness of the show.

\section{CONCLUSIONS}

In conclusion, what has been discussed above concerning the phenomenon of acculturation in translation of musicals can be summarized in a three-dimensional framework illustrated in Fig. 2.

1) As for the first dimension, the paper suggests that acculturation is inevitable and remarkable in translation of musicals due to three factors, namely cultural differences, audience reception, and the audiovisual constraints of music and performance.

2) As for the second dimension, it argues that the target text of a musical should satisfy the requirements of comprehensibility, acceptability, and enjoyability (subdivided into singability and interactivity) for the target audience.

3) As for the third dimension, the paper recommends that a translator, as a cultural mediator, has to acculturate the target text adopting some typical strategies. First, to assure the comprehensibility of the target text, a translator needs to adapt those culture-loaded expressions that are difficult for the target audience to understand. Second, to improve the acceptability of the target text in the target culture, he or she needs to filter the information of possible cultural conflicts. Third, the requirement of enjoyability can be subdivided into singablity and interactivity according to the musical and theatrical qualities of musicals. As for singability, the translator should aim for producing a target text compatible with the pre- existing music, and often has to make proper adaptations of the lyrics to the target-culture genre conventions of song lyrics. As for interactivity, the translator attends to the future performing atmosphere usually by making recreationalized adjustments.

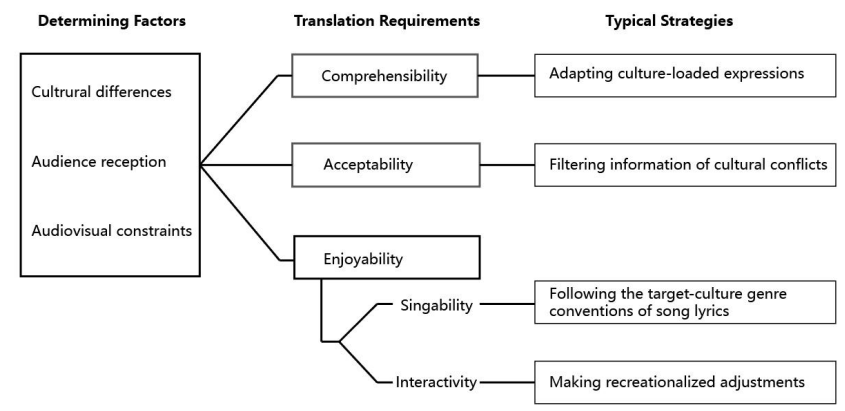

Fig. 2. A three-dimensional framework of acculturation in translation of musicals.

With the further development of intercultural communication between Chinese and western theatrical arts, more and more musicals will be introduced into China. How to balance the reproduction and acculturation of the exotic elements in translation of musicals might constitute a new issue deserving further exploration. Moreover, it is also hoped that the paper will draw attention from more scholars and spark their interest in the newly emerging and most neglected area, i.e. the translation of musicals.

\section{REFERENCES}

[1] R. Redfield, R. Linton, and M. J. Herskovits, "Memorandum for the study of acculturation," American Anthropologist, Vol. 1, pp. 149-152, 1936.

[2] S. Aaltonen, "Rewriting the Exotic: The Manipulation of Otherness in Translated Drama," in Translation - the Vital Link: Proceedings of XIII FIT World Congress, C. Pichen Ed., Institute of Translation and Interpreting, London, 1993, pp. 26-33.

[3] S. Aaltonen, Acculturation of the Other: Irish Milieux in Finnish Drama Translation. Joensuu: Joensuu University Press, 1996.

[4] B. He, "On the Similarities and Differences between Chinese Operas and Western Musicals," Sichuan Drama, Vol. 6, pp. 20-22, 2004. (In Chinese)

[5] R. C. Holub, Reception Theory: A Critical Introduction. London: Methyen, 1984.

[6] E. A. Nida, Language, Culture, and Translating. Shanghai: Shanghai Foreign Language Education Press, 1993.

[7] S. Bassnett. Translation Studies, 3rd ed. London \& New York: Routledge, 2002.

[8] J. Franzon, "Choices in Song Translation: Singability in Print, Subtitles and Sung Performance," The Translator, Vol. 2, pp. 373-399, 2008.

[9] F. Xue, Exploration and Practice of Song Translation. Wuhan: Hubei Education Press, 2002. (In Chinese)

[10] E. Nilolarea, "Performability versus Readability: A Historical Overview of a Theoretical Polarization in Theatre Translation," Translation Journal Vol. 4, 2002. http://translationjournal.net/journal/22theater.htm.

[11] P. Pavis, "Problems of Translation for the Stage: Intercultural and PostModern Theatre," in The Play Out of Context: Transferring Plays from Culture to Culture, H. Scolnicov and P. Holland, Eds. Cambridge: Cambridge University Press, 1989, pp. 25-34. 